\title{
Effect of warfarin versus aspirin on blood viscosity in cardioembolic stroke with atrial fibrillation: a prospective clinical trial
}

\author{
Chan-Hyuk Lee ${ }^{1,2}$, Keun-Hwa Jung ${ }^{1}$, Daniel J. Cho ${ }^{3}$ and Seul-Ki Jeong ${ }^{2, *^{*}}$
}

\begin{abstract}
Background: Warfarin is evidence-based therapy for the prevention of cardioembolic stroke, but has not been studied for its effects on whole blood viscosity (WBV). This study investigated the effect of warfarin versus aspirin on WBV in patients presenting with non-valvular atrial fibrillation (NVAF) and acute cardioembolic stroke.

Methods: We enrolled patients with acute cerebral infarction, aged 56-90 years who had NVAF, CHADS 2 score $\geq 2$, presenting with mild-to-moderate stroke (National Institute of Health Stroke Scale (NIHSS) score $<20$ and modified Rankin Scale $(2 \mathrm{mRS})$ score $<4)$ in a single center. The patients were alternately assigned to warfarin or aspirin groups. Post-treatment WBV was assessed after international normalized ratio (INR) reached target range [2, 3] for patients in the warfarin group, and 5 days after baseline in the aspirin group.
\end{abstract}

Results: Total 67 patients were included, and 56 completed this study (33 warfarin and 23 aspirin). Compared to baseline values, warfarin reduced post-treatment BV at all shear rates. The BV reductions greater than $1 \mathrm{cP}$ measured at shear rates of $300,150,5$, and $1 \mathrm{~s}^{-1}$ were independently and significantly associated with warfarin treatment compared to aspirin after adjusting for age, sex, $\mathrm{CHA}_{2} \mathrm{DS}_{2}$-VASC scores, and baseline hematocrit.

Conclusions: Warfarin confers greater reductions in $\mathrm{BV}$ than aspirin in patients with acute cardioembolic stroke. BV could be a useful method to estimate thrombotic risk in patients receiving warfarin.

Trial registration: KCT0001291, Date of Registration: 2014-12-01

Keywords: Atrial fibrillation, Cardioembolic stroke, Warfarin, Whole blood viscosity

\section{Background}

Whole blood viscosity (WBV) is defined as the internal resistance of blood flow and it determines the frictional force applied to the vessel wall. The WBV has been reported to be independently associated with the cardiovascular risk factors, such as hypertension, diabetes, hyperlipidemia, obesity, and cigarette smoking [1]. The previous epidemiologic studies have shown that the WBV was significantly and positively associated with the higher occurrence of major cardiovascular events, including

\footnotetext{
*Correspondence: jeongsk@jbnu.ac.kr

${ }^{2}$ Department of Neurology, Chonbuk National University Hospital, Jeonju, South Korea

${ }^{4}$ Department of Neurology \& Research Institute of Clinical Medicine, Chonbuk National University Medical School - Biomedical Research Institute of Chonbuk National University Hospital, Geonjiro 20, Deokjin-gu, Jeonju, Chonbuk 54907, South Korea

Full list of author information is available at the end of the article
}

cardiovascular death $[2,3]$. The WBV is a component to calculate arterial wall shear stress which is a biomechanical tangential force along the arterial wall $[4,5]$. Mathematically, it can be simplified to $\tau=\mu \times \gamma$. Where $\tau$ is the shear stress, $\mu$ is the viscosity, and $\gamma$ is the shear rate [5]. Shear rate is the change in blood velocity relative to the inner diameter of the vessel and ranges between 20 and $500 / \mathrm{s}$. Shear stress is the frictional resistance of the blood to the blood vessel walls.

Warfarin is evidence-based therapy for the prevention of cardioembolic ischemic stroke in patients with non-valvular and valvular atrial fibrillation (AF). If concentration of warfarin in blood does not reach therapeutic levels in patients with AF, ischemic stroke cannot be effectively prevented [6] and if warfarin is overdosed, bleeding tendency is increased [7]. Therefore, proper use of warfarin is important to prevent cardioembolic stroke. 
International normalized ratio (INR) is widely used as a means of monitoring the effect of warfarin. However, the results may differ for each reagent manufacturer used for the INR measurement, as international sensitivity index (ISI) is required to calculate INR, which demonstrates the variability of the INR value even for the same sample [8-10]. Previous studies have also shown that INR variability is also high in the external quality assurance data. In addition, it has been reported that the laboratory INR and the point-of-care INR were different from each other [11, 12].

Considering the pharmaceutical effects of warfarin on blood clotting factors, we assumed that it could affect the levels of the WBV according to the concentration of the drug. No previous study has examined whether the WBV could be changed in the therapeutic ranges of warfarin in patients with atrial fibrillation. Meanwhile, there were studies on the association between aspirin and WBV. There was no statistically significant difference of WBV between the aspirin group and the placebo group in the unadulterated blood sample [13]. Other studies that measured blood viscosity and red cell deformability in healthy adults did not show any difference between before and after aspirin administration [14].

For the purpose, this study investigated the effects of warfarin and aspirin on blood viscosity in cardioembolic ischemic stroke patients with non-valvular atrial fibrillation (NVAF).

\section{Methods}

\section{Patient population}

This is a prospective, alternately assigned, open-label and blinded-endpoint clinical trial. We enrolled patients aged 56-90 years in acute stage of ischemic stroke. Presentation of acute ischemic stroke was defined as high signal intensity in a diffusion weighted image and low signal intensity in an apparent diffusion coefficient simultaneously with brain magnetic resonance image among patients experienced symptoms of stroke within 7 days. Transthoracic echocardiography was performed on patients with AF identified in the electrocardiography, and only patients with non-valvular type were finally enrolled in the study. In addition, according to the Trial of Org 10,172 in Acute Stroke Treatment (TOAST) classification, we further confirmed whether the patient was eligible for cardioembolic stroke.

Among the patients, only individuals with mild-to-moderate stroke (National Institute of Health Stroke Scale (NIHSS) score $<20$ and modified Rankin Scale (mRS) score $<4$ ) were selected to exclude patients with severe neurological deterioration. Patients with severe stroke with high NIHSS often have large ischemic stroke [15], and have an increased risk of hemorrhagic transformation.
This increases the possibility of alteration or discontinuation of antithrombotic agents [16].

In order to select only patients who need anticoagulation, we reaffirmed whether $\mathrm{CHADS}_{2}$ score is over 2 . $\left(\mathrm{CHADS}_{2}\right.$ score: $\mathrm{C}$, congestive heart failure; $\mathrm{H}$, hypertension; A, $\geq 75$ years; D, diabetes mellitus; $S_{2}$, prior stroke, transient ischemic attack or thromboembolism).

Patients were excluded if they were pregnant or lactating, previously treated with anticoagulants or steroids, or if they had hemorrhagic stroke, endocarditis, severe mitral stenosis or mechanical heart valve replacement, hematologic, hepatic, renal diseases or malignancy. Additionally, transient atrial fibrillation after surgery, high risk of bleeding, hemoglobin $<7.0 \mathrm{mg} / \mathrm{dl}$, probability of blood transfusion during the trial, platelet $>450,000 / \mu \mathrm{L}$, platelets $<90,000 / \mathrm{uL}$, uncontrolled diabetes mellitus and hypertension were excluded from the study. Patients were alternately assigned according to the order of enrollment, and the warfarin group was set to open-label study for appropriate INR control. This study was approved by the Institutional Review Board of the Biomedical Research Institute of Chonbuk National University Hospital and registered in Clinical Research Information Service in Korea (CRIS Reg No. KCT0001291). All participants provided written informed consent.

\section{Laboratory data}

Complete blood counts, blood lipid profile, renal function, liver function, $\mathrm{HbA1c}$, urine albumin-to-creatinine ratio, homocysteine, and blood coagulation factors such as prothrombin time (PT), activated partial thromboplastin time (aPTT), and D-dimer were tested using standard methods. In particular, the blood for the INR, $\mathrm{PT}$, and aPTT is contained in a sodium citrate tube, and the plasma is automatically analyzed using an ACL TOP (Werfen, Australia) analyzer.

To measure the WBV, $3-5 \mathrm{~mL}$ of whole blood from each patient was collected from peripheral vein and agitated gently in ethylenediaminetetraacetic acid (EDTA) tube. The blood was refrigerated at $4{ }^{\circ} \mathrm{C}$ until analysis. The WBV was measured using a computerized scanning capillary viscometer (Hemathix, King of Prussia, PA) which provided the WBV at shear rates of 1 to $1000 / \mathrm{s}$ at increments of $0.1 / \mathrm{s}$. The WBV was measured within $36 \mathrm{~h}$ of sampling, and the blood was maintained at $37^{\circ} \mathrm{C}$ during the analysis.

\section{Outcome measure and sample volume estimation}

The primary outcome measures were changes in WBV at high and low shear rates (300 and 5/s respectively). For the purpose of that, baseline WBV was assessed before treatment. Post-treatment WBV was assessed after reaching the therapeutic range (INR 2-3) for patients in warfarin group. Aspirin group received $300 \mathrm{mg}$ of aspirin on the first day, and $100 \mathrm{mg}$ was given for the next 5 days before blood analysis. 
All the patients who were enrolled in the present study began to receive warfarin within 14 days after the onset of neurological symptoms which was in accordance with the current guidelines [17].

In a previous study using scanning capillary viscometer in patients classified as high-risk for cardiovascular disease based on a Framingham risk equivalent of $>20 \%$, standard deviation of mean WBV levels at low shear rate $(5 / \mathrm{s})$ were reported as $2.42 \mathrm{cP}$ [18]. We enrolled 50 subjects to detect a change of one standard deviation (SD) in mean low-shear blood viscosity or 25 subjects in each of 2 arms using $90 \%$ power and a type 1 error rate of $5 \%$.

\section{Statistical analysis}

Descriptive data for the major characteristics were expressed as means \pm SDs or percentages as appropriate. Independent t-test or chi-square test was used to determine the statistical differences between the two groups. For the WBV, paired t-tests (Wilcoxon signed rank tests) were performed to compare the treatment effects. For a logistic regression analysis, blood viscosity reductions $1 \mathrm{cP}$ or more was set to be a dependent variable and the association with treatment modality was examined for an independency. Statistical analysis was performed by the third-party statistician and conducted using SAS (SAS, Cary, NC) and SPSS Statistics 20 (SPSS, Chicago, IL).

\section{Results}

\section{Study population}

Total 67 patients were included, and 56 completed the trial (33 warfarin and 23 aspirin). Eleven patients were dropped out after study inclusion due to noncompliance, withdrawal of consent, and transition to other drugs (Fig. 1). When comparing dropouts and patients completing the study, there was no significant differences in age, sex, $\mathrm{CHA}_{2} \mathrm{DS}_{2}$-VASc scores, or treatment arm assignment (data are not shown, all $p$ values $>0.1$ ).

\section{Basic characteristics}

There was no significant difference between the warfarin and aspirin group, including demographic and laboratory findings, as shown in Table 1 . As for clinical profiles, all the NIHSS, mRS, $\mathrm{CHADS}_{2}$ or $\mathrm{CHA}_{2} \mathrm{DS}_{2}$-VASc scores did not show any significant difference between the two groups.

\section{Blood viscosity of warfarin and aspirin}

There was no significant difference of baseline levels of WBV between the two groups (Table 2). In the warfarin group, the INR was $1.12 \pm 0.19$ (mean \pm SD) versus $2.37 \pm 0.48(p<0.001)$ before and after warfarin administration. After the treatments, warfarin numerically reduced post-treatment blood viscosity at all shear rates when INR reached target ranges (Fig. 2, Table 3). These differences were statistically significant at shear rates of $150(p=0.032), 100(p=0.022), 50(p=$ $0.014), 10(p=0.033)$, and $5 / \mathrm{s} \quad(p=0.034)$. At shear rates of 300 and $1 / \mathrm{s}$, marginal significances were observed ( $p=0.055$ and 0.071 , respectively). In contrast, aspirin had no effect on blood viscosity compared to pre-treatment state $(p>0.05$, Table 4$)$.

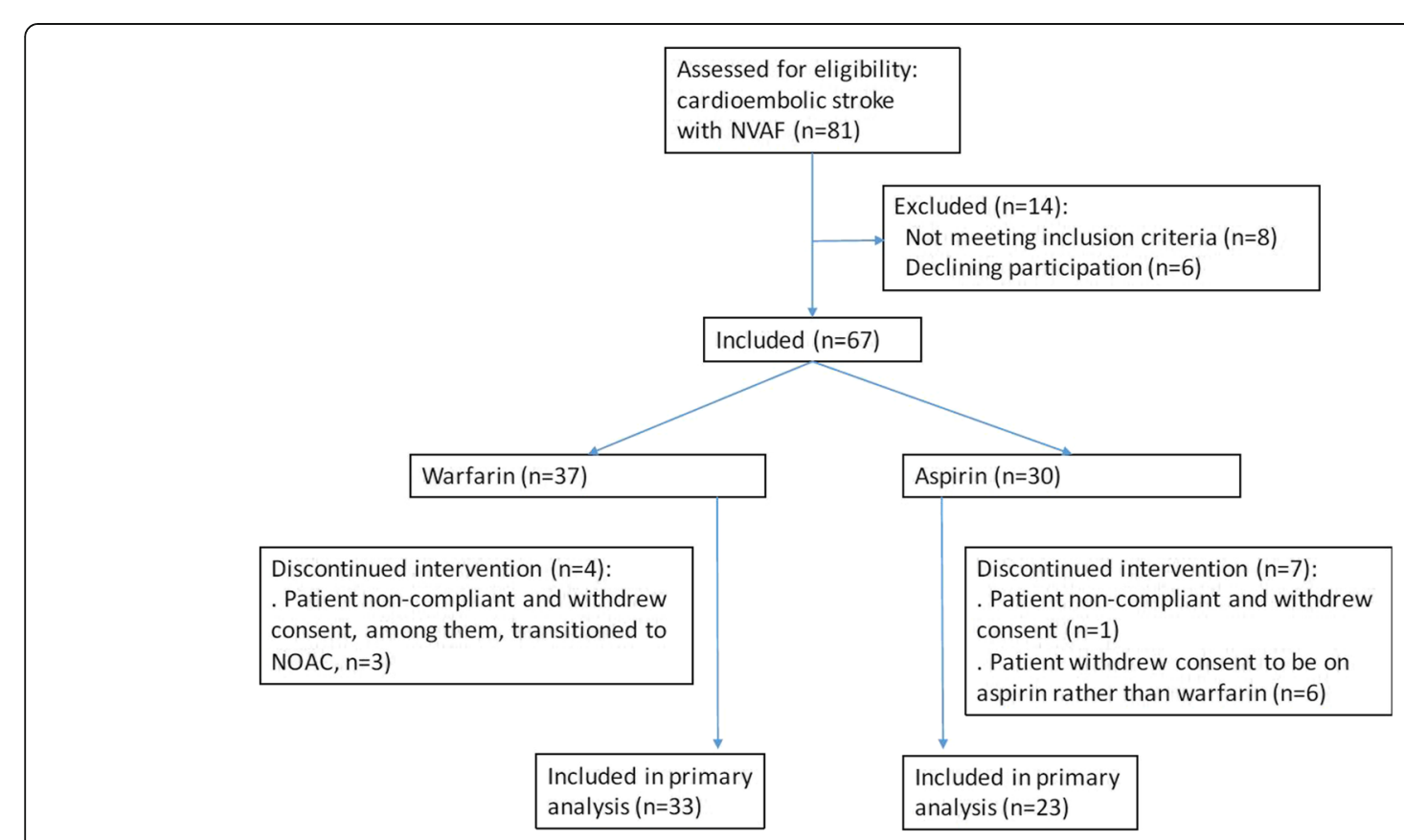

Fig. 1 Flowchart of patient's selection 
Table 1 Demographics of patients with ischemic stroke patients

\begin{tabular}{|c|c|c|c|}
\hline \multirow[t]{2}{*}{ Variables $^{\mathrm{a}}$} & \multicolumn{2}{|c|}{ Aspirin versus warfarin } & \multirow[t]{2}{*}{$p$ value* } \\
\hline & $\begin{array}{l}\text { Aspirin } \\
(n=23)\end{array}$ & $\begin{array}{l}\text { Warfarin } \\
(n=33)\end{array}$ & \\
\hline Age, years & $72.2 \pm 8.6$ & $74.2 \pm 8.3$ & 0.389 \\
\hline Female, $n(\%)$ & $11(47.8)$ & $17(51.5)$ & 0.786 \\
\hline \multicolumn{4}{|l|}{ Clinical Profiles } \\
\hline $\mathrm{CHADS}_{2}$ & $3.2 \pm 0.9$ & $3.5 \pm 0.8$ & 0.232 \\
\hline $\mathrm{CHA}_{2} \mathrm{DS}_{2}-\mathrm{VASC}$ & $4.4 \pm 1.3$ & $4.9 \pm 1.2$ & 0.238 \\
\hline NIHSS, initial & $6.4 \pm 6.2$ & $5.6 \pm 6.0$ & 0.613 \\
\hline mRS, initial & $2.3 \pm 1.7$ & $2.5 \pm 1.7$ & 0.669 \\
\hline \multicolumn{4}{|l|}{ Laboratory Data } \\
\hline White blood cell, $\times 10^{3} / \mu$ l & $7.8 \pm 2.7$ & $7.5 \pm 3.2$ & 0.716 \\
\hline Hematocrit, \% & $37.0 \pm 6.3$ & $37.4 \pm 5.7$ & 0.803 \\
\hline Platelet, $\times 10^{3} / \mu \mathrm{l}$ & $192.8 \pm 44.1$ & $219.9 \pm 59.1$ & 0.068 \\
\hline PT, \% & $93.1 \pm 12.0$ & $85.0 \pm 12.5$ & 0.051 \\
\hline aPTT, second & $27.1 \pm 7.6$ & $30.7 \pm 18.1$ & 0.371 \\
\hline D-dimer, mg/L & $2.4 \pm 3.6$ & $2.4 \pm 2.7$ & 0.959 \\
\hline Albumin, g/dL & $5.6 \pm 8.8$ & $5.2 \pm 7.2$ & 0.854 \\
\hline Total protein, g/dL & $6.6 \pm 0.8$ & $6.7 \pm 0.8$ & 0.479 \\
\hline Creatinine, mg/dL & $0.8 \pm 0.3$ & $1.3 \pm 2.4$ & 0.296 \\
\hline eGFR, $\mathrm{mL} / \mathrm{min} / 1.73 \mathrm{~m}^{2}$ & $84.7 \pm 19.0$ & $85.1 \pm 17.8$ & 0.940 \\
\hline Total cholesterol, mg/dL & $153.1 \pm 30.2$ & $155.3 \pm 28.0$ & 0.776 \\
\hline Triglyceride, mg/dL & $95.2 \pm 39.8$ & $90.4 \pm 36.3$ & 0.638 \\
\hline $\begin{array}{l}\text { High density lipoprotein, mg/ } \\
\text { dL }\end{array}$ & $47.2 \pm 13.9$ & $47.5 \pm 14.2$ & 0.951 \\
\hline $\mathrm{HbA} 1 \mathrm{c}, \%$ & $5.9 \pm 0.4$ & $6.0 \pm 0.5$ & 0.763 \\
\hline UACR, mg/g & $\begin{array}{l}114.8 \pm \\
116.8\end{array}$ & $\begin{array}{l}160.8 \pm \\
203.8\end{array}$ & 0.334 \\
\hline Homocysteine, $\mu \mathrm{mol} / \mathrm{L}$ & $16.2 \pm 4.6$ & $17.5 \pm 13.1$ & 0.654 \\
\hline
\end{tabular}

*Independent T-test was used for numerical values and chi square test for categorical value

${ }^{a}$ Values are presented mean $\pm S D$, unless indicated otherwise $\mathrm{CHADS}_{2}: C$ congestive heart failure, $H$ hypertension, $A \geq 75$ years; $D$ diabetes mellitus, $S_{2}$ prior stroke, transient ischemic attack or thromboembolism, $\mathrm{CHA}_{2} \mathrm{DS}_{2}$ VASc: $C$ congestive heart failure, $H$ hypertension, $A_{2} \geq 75$ years, $D$ diabetes mellitus, $S_{2}$ prior stroke, transient ischemic attack or thromboembolism, $V$ vascular disease, $A$ 65-74 years, Sc sex category, NIHSS National Institutes of Health Stroke Scale, $m R S$ modified Rankin Scale, PT prothrombin time, aPTT activated partial thromboplastin time, BUN blood urea nitrogen, eGFR estimated glomerular filtration rate, UACR urine albumin-to-creatinine ratio

Blood viscosity decreased by more than $1 \mathrm{cP}$ at each shear rate was also evaluated using a multiple logistic regression model. At shear rates of $300,150,5$, and $1 / \mathrm{s}$, the blood viscosity was independently and significantly associated with warfarin compared to aspirin after adjusting for age, sex, $\mathrm{CHA}_{2} \mathrm{DS}_{2}$-VASc scores, and baseline hematocrit (Table 5).

\section{Discussion}

This study investigated the effect of warfarin or aspirin on the WBV in cardioembolic stroke patients with NVAF.
Table 2 Baseline whole blood viscosity of aspirin and warfarin group

\begin{tabular}{llll}
\hline \multirow{2}{*}{$\begin{array}{l}\text { Shear } \\
\text { rate }\end{array}$} & \multicolumn{2}{l}{ Whole blood viscosity $(c P$, baseline $)$} & $p$ value $^{\S}$ \\
\cline { 2 - 3 } & Aspirin group & Warfarin group & \\
\hline $1000 / \mathrm{s}$ & 3.39 & 3.57 & 0.835 \\
$300 / \mathrm{s}$ & 3.81 & 3.81 & 0.910 \\
$150 / \mathrm{s}$ & 4.17 & 4.17 & 0.977 \\
$100 / \mathrm{s}$ & 4.41 & 4.31 & 0.953 \\
$50 / \mathrm{s}$ & 4.97 & 4.84 & 0.871 \\
$10 / \mathrm{s}$ & 7.43 & 7.67 & 0.865 \\
$5 / \mathrm{s}$ & 9.7 & 10.42 & 0.768 \\
$1 / \mathrm{s}$ & 23.01 & 25.53 & 0.535 \\
\hline
\end{tabular}

${ }^{5}$ Independent T-test was used

There was no difference in blood viscosity after the administration of aspirin, but the viscosity of the warfarin group decreased at all shear rates. This is the first study to reveal the relationship between the WBV and warfarin in patients with atrial fibrillation. The WBV has been thought of as an emerging risk marker for vascular diseases and mortality $[19,20]$. Therefore, anti-viscogenic effects of warfarin on WBV may be considered carefully.

The associations between cardiovascular risk factors and the WBV were reported previously [21]. As for stroke, there have been several reports on the relationship between stroke and blood viscosity [22, 23]. Relative blood viscosity (WBV divided by plasma viscosity) in the patients with ischemic stroke was increased in the acute phase [24]. The British Regional Heart Study, with 9.5 years of follow up, showed that the high hematocrit level increased the incidence of stroke [25]. The severity of spontaneous echo contrast (SEC) in patients with acute or chronic cerebrovascular disease was associated with increased plasma and serum viscosity [26].

Anticoagulants, such as warfarin or heparin, inhibit the activities of coagulation factors and prevent blood clotting. It has been reported for the relationship between the blood viscosity and some kinds of anticoagulants. Heparin and argatroban have been shown to decrease blood viscosity in a dose-dependent manner in healthy human samples $[27,28]$. As for mucopolysaccharide polysulfate, the WBV was also decreased in healthy adults dose-dependently [29]. Although the present study was not designed to reveal the dose-dependent manner of WBV reduction by warfarin, the WBV has been reported to be reduced with anticoagulants. The relationship between non-vitamin $\mathrm{K}$ dependent anticoagulant and the WBV in atrial fibrillation has not reported yet.

Compared to anticoagulants, antiplatelet agents showed various responses. As for aspirin, the previous study showed that the WBV did not change at any dose of aspirin [13]. In the present study, the blood viscosity values 


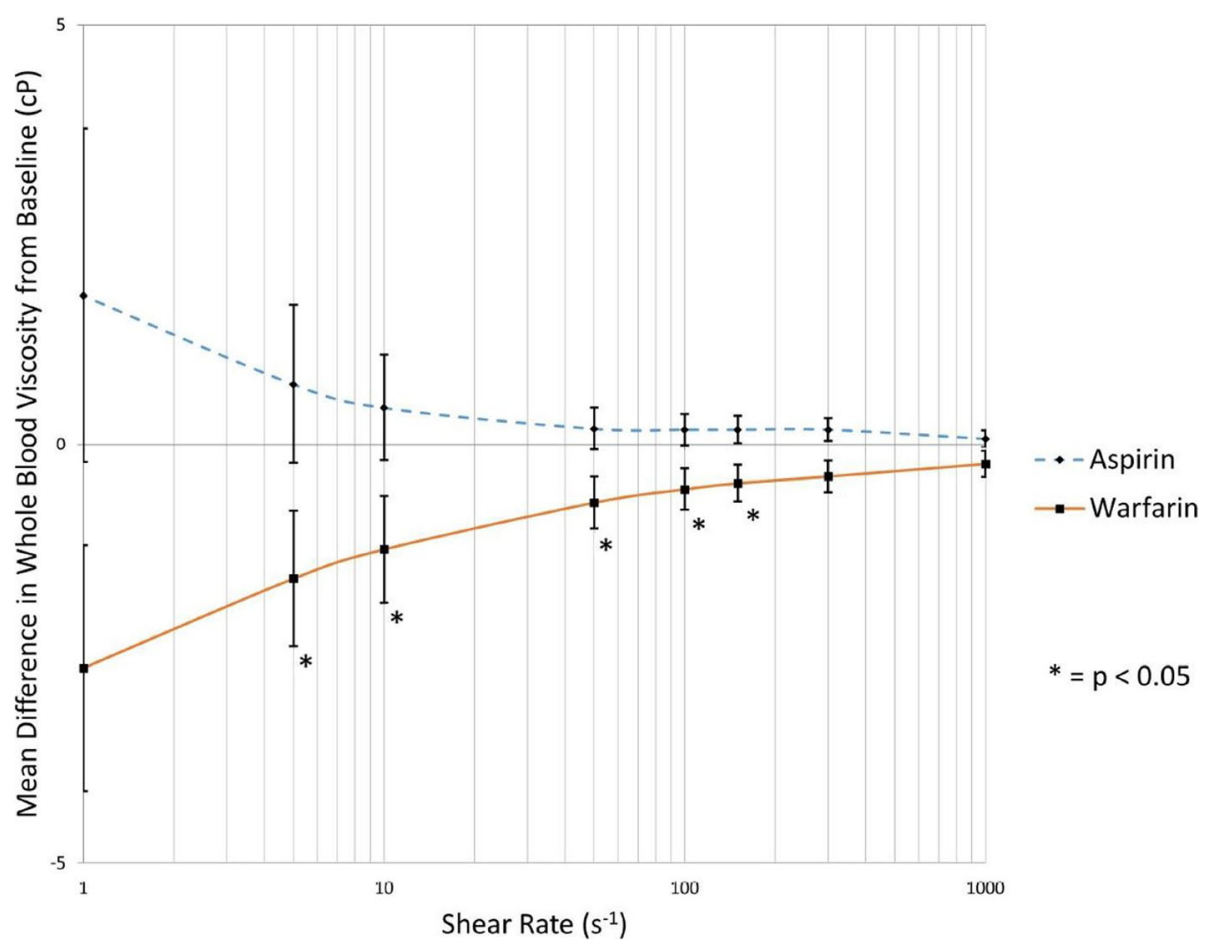

Fig. 2 Mean difference of warfarin and aspirin in whole blood viscosity from baseline. Warfarin numerically reduced post-treatment blood viscosity at all shear rates

at all measured shear rates did not show any significant change after aspirin treatment, which was similar with previous studies. Other prior reports have shown the effects of various antiplatelet agents on WBV; no response with aspirin and cilostazol [30], but lowering responses with dipyridamole and clopidogrel on WBV $[18,31]$. Clinical trials of antiplatelet agents or their combinations have been performed for their effectiveness on ischemic cardiocerebrovascular diseases or for safety issues. The antiplatelet agents or their combinations showed diverse clinical outcome according to cardio- or cerebrovascular diseases

Table 3 The difference in blood viscosity before and after treatment in the warfarin group

\begin{tabular}{llll}
\hline \multirow{2}{*}{$\begin{array}{c}\text { Shear } \\
\text { rate }\end{array}$} & \multicolumn{2}{l}{ Whole blood viscosity $(\mathrm{cP}$, baseline) } & $p$ value \\
\cline { 2 - 3 } & Baseline (mean \pm SD) & After treatment (mean \pm SD) & \\
\hline $1000 / \mathrm{s}$ & $3.88 \pm 0.99$ & $3.64 \pm 0.60$ & 0.135 \\
$300 / \mathrm{s}$ & $4.29 \pm 1.21$ & $3.90 \pm 0.63$ & 0.047 \\
$150 / \mathrm{s}$ & $4.61 \pm 1.42$ & $4.14 \pm 0.70$ & 0.039 \\
$100 / \mathrm{s}$ & $4.85 \pm 1.60$ & $4.31 \pm 0.76$ & 0.036 \\
$50 / \mathrm{s}$ & $5.44 \pm 2.02$ & $4.74 \pm 0.93$ & 0.031 \\
$10 / \mathrm{s}$ & $8.77 \pm 4.06$ & $7.52 \pm 1.75$ & 0.058 \\
$5 / \mathrm{s}$ & $11.67 \pm 5.21$ & $10.05 \pm 2.54$ & 0.056 \\
$1 / \mathrm{s}$ & $27.41 \pm 9.59$ & $24.73 \pm 7.79$ & 0.078
\end{tabular}

${ }^{5}$ Paired T-test was used. $S D$ standard deviation
$[32,33]$. Given that the WBV responses, it might be considered whether WBV can be adjusted according to target organ or disease categories.

Warfarin showed superiority to aspirin in the patients with ischemic stroke and valvular or non-valvular AF [34]. Considering the WBV-lowering effect of warfarin, this suggests that the WBV effect may be more important in cardiogenic stroke including AF than non-cardiogenic stroke, such as large artery atherosclerosis. The pathophysiological mechanism that causes the ischemic stroke in cardiogenic stroke is multifactorial but can be described

Table 4 The difference in blood viscosity before and after treatment in the aspirin group

\begin{tabular}{llll}
\hline $\begin{array}{l}\text { Shear } \\
\text { rate }\end{array}$ & \multicolumn{2}{l}{ Whole blood viscosity $(\mathrm{cP}$, baseline $)$} & $p$ value \\
\cline { 2 - 3 } & Baseline $($ mean $\pm \mathrm{SD})$ & After treatment $($ mean $\pm \mathrm{SD})$ & \\
\hline $1000 / \mathrm{s}$ & $3.51 \pm 0.62$ & $3.58 \pm 0.52$ & 0.498 \\
$300 / \mathrm{s}$ & $3.81 \pm 0.75$ & $3.99 \pm 0.61$ & 0.199 \\
$150 / \mathrm{s}$ & $4.09 \pm 0.87$ & $4.27 \pm 0.72$ & 0.273 \\
$100 / \mathrm{s}$ & $4.31 \pm 0.98$ & $4.49 \pm 0.83$ & 0.344 \\
$50 / \mathrm{s}$ & $4.85 \pm 1.26$ & $5.04 \pm 1.09$ & 0.467 \\
$10 / \mathrm{s}$ & $7.72 \pm 2.57$ & $8.16 \pm 2.55$ & 0.495 \\
$5 / \mathrm{s}$ & $10.22 \pm 3.62$ & $10.94 \pm 3.85$ & 0.454 \\
$1 / \mathrm{s}$ & $23.95 \pm 8.90$ & $25.73 \pm 8.46$ & 0.383 \\
\hline SPaired T-test was used & &
\end{tabular}


Table 5 Multivariate ${ }^{a}$ association between blood viscosity decrease more than $1 \mathrm{cP}$ and warfarin (compared to aspirin)

\begin{tabular}{llll}
\hline \multirow{2}{*}{$\begin{array}{l}\text { Shear } \\
\text { rate }\end{array}$} & \multicolumn{2}{l}{ Blood viscosity decrease more than 1 cP } & \\
\cline { 2 - 3 } & Odds ratio & $95 \% \mathrm{Cls}$ & \\
\hline $1000 / \mathrm{s}$ & 0.28 & $0.08-1.01$ & 0.051 \\
$300 / \mathrm{s}$ & 3.71 & $1.04-13.17$ & 0.043 \\
$150 / \mathrm{s}$ & 4.30 & $1.20-15.49$ & 0.026 \\
$100 / \mathrm{s}$ & 3.37 & $0.99-11.50$ & 0.053 \\
$50 / \mathrm{s}$ & 2.72 & $0.86-8.60$ & 0.089 \\
$10 / \mathrm{s}$ & 2.81 & $0.84-9.39$ & 0.093 \\
$5 / \mathrm{s}$ & 3.35 & $1.00-11.25$ & 0.050 \\
$1 / \mathrm{s}$ & 4.38 & $1.31-14.64$ & 0.017 \\
\hline
\end{tabular}

${ }^{a}$ Adjusted for age, sex, $\mathrm{CHA}_{2} \mathrm{DS}_{2}-\mathrm{VASc}$, and hematocrit

conceptually in relation to Virchow's triad for thrombogenesis. These components comprise abnormal blood stasis in the atria, structural heart disease and abnormalities of blood coagulation [35]. Atrial fibrillation causes a structural change in left atrium (LA) and appendage, leading to a larger diameter, which increases the likelihood of blood stasis. A previous study reported that the size of the LA corrected by body surface area is an independent risk factor for stroke occurrence [36]. Atrial fibrillation also changes the composition of blood clotting factors, including fibrin and thrombin-antithrombin complexes, which promote thrombus formation [37]. These hemorrheological changes in AF might be improved by warfarin with reduced effects of WBV.

The WBV provides an absolute value, rather than a relative comparison to a reference like INR. It implies that the WBV could be used to stratify and predict the risk of the future ischemic cerebrovascular diseases. Previous reports on normative data might be useful to identify the abnormal distributions of the WBV in patients with vascular diseases [38]. When analyzing the WBV, the principal determinants which include hematocrit, red blood cell deformability, and plasma viscosity might be considered as well.

Limitations of the present study includes: first, the relatively small sample size with modest drop rates. However, compared to the previous studies in which healthy individuals were enrolled, the present study was performed in the patients with acute ischemic stroke. The higher drop rate in the aspirin arm, which could increase the chance of type 2 error, might be caused by the selection only in the patients. Second, the WBV was measured when INR reached target ranges in the warfarin group, so we could not show whether the WBV could be reduced further at higher concentrations of warfarin. Lastly, since this study was conducted in Asia, that is, in Korea, it is premature to generalize the effect of warfarin on the WBV on global populations. To clarify the relationship between warfarin and the WBV, subsequent multi-ethnic studies are needed.

In conclusion, warfarin reduced the WBV significantly in patients with acute ischemic stroke with NVAF, compared to aspirin. The reduction in blood viscosity with warfarin may provide an integrated measure on thrombotic risk. Further studies are needed to evaluate the usefulness of WBV in the prediction of stroke at the time of clinical presentation, and the effects of WBV reductions with warfarin therapy on the risk of recurrent stroke in various etiologies of ischemic stroke including cardiogenic stroke.

\section{Abbreviations}

AF: atrial fibrillation; BV: blood viscosity; INR: international normalized ratio; LA: left atrium; mRS: modified Rankin Scale; NIHSS: National Institute of Health Stroke Scale; NOAC: non-vitamin K antagonist oral anticoagulant; NVAF: non-valvular atrial fibrillation; SLE: Systemic Lupus Erythematosus

\section{Acknowledgements}

Not applicable.

\section{Funding}

Biomedical Research Institute, Chonbuk National University Hospital [grant numbers CUH2014-05019002] was not involved in data collection, analysis, or writing a paper at all, except for funding.

\section{Availability of data and materials}

The datasets used and analysed during the current study are available from the corresponding author on reasonable request.

\section{Authors' contributions}

$\mathrm{CH}$ contributed to data collection, analysis and draft the paper. $\mathrm{KH}$ organized the data and advised on the direction of the study. DJ was dedicated to the paper revision. SK set up the research topic, analyzed the data, and made the final revision of the paper. All authors have read and approved the manuscript of our research.

\section{Ethics approval and consent to participate}

This study was approved by the Institutional Review Board of the Biomedical Research Institute of Chonbuk National University Hospital and registered in Clinical Research Information Service in Korea (CRIS Reg No. KCT0001291). All participants provided written informed consent.

Consent for publication

Not applicable.

\section{Competing interests}

The authors declare that they have no competing interests.

\section{Publisher's Note}

Springer Nature remains neutral with regard to jurisdictional claims in published maps and institutional affiliations.

\section{Author details}

${ }^{1}$ Department of Neurology, Seoul National University Hospital, Seoul, South Korea. ${ }^{2}$ Department of Neurology, Chonbuk National University Hospital, Jeonju, South Korea. ${ }^{3}$ Rheovector, LLC, King of Prussia, PA, USA. ${ }^{4}$ Department of Neurology \& Research Institute of Clinical Medicine, Chonbuk National University Medical School - Biomedical Research Institute of Chonbuk National University Hospital, Geonjiro 20, Deokjin-gu, Jeonju, Chonbuk 54907 South Korea. 
Received: 9 February 2019 Accepted: 22 April 2019

Published online: 01 May 2019

\section{References}

1. Celik T, Yilmaz MI, Balta S, Ozturk C, Unal HU, Aparci M, et al. The relationship between plasma whole blood viscosity and cardiovascular events in patients with chronic kidney disease. Clin Appl Thromb Hemost. 2017;23(6):663-70.

2. Peters SA, Woodward M, Rumley A, Tunstall-Pedoe HD, Lowe GD. Plasma and blood viscosity in the prediction of cardiovascular disease and mortality in the Scottish heart health extended cohort study. Eur J Prev Cardiol. 2017; 24(2):161-7.

3. Lowe G, Rumley A, Norrie J, Ford I, Shepherd J, Cobbe S, et al. Blood rheology, cardiovascular risk factors, and cardiovascular disease: the west of Scotland coronary prevention study. Thromb Haemost. 2000;84(4):553-8.

4. Gnasso A, Carallo C, Irace C, Spagnuolo V, De Novara G, Mattioli PL, et al Association between intima-media thickness and wall shear stress in common carotid arteries in healthy male subjects. Circulation. 1996;94(12): 3257-62.

5. Jeong SK, Rosenson RS. Shear rate specific blood viscosity and shear stress of carotid artery duplex ultrasonography in patients with lacunar infarction. BMC Neurol. 2013;13:36.

6. Merli GJ, Tzanis G. Warfarin: what are the clinical implications of an out-ofrange-therapeutic international normalized ratio? J Thromb Thrombolysis. 2009;27(3):293-9.

7. Baglin T. Management of warfarin (coumarin) overdose. Blood Rev. 1998; 12(2):91-8.

8. Favaloro EJ, McVicker W, Hamdam S, Hocker N. Improving the harmonisation of the international normalized ratio (INR): time to think outside the box? Clin Chem Lab Med. 2010:48(8):1079-90.

9. Jennings I, Kitchen DP, Woods TA, Kitchen S, Walker ID. Emerging technologies and quality assurance: the United Kingdom National External Quality Assessment Scheme perspective. Semin Thromb Hemost. 2007;33(3): 243-9.

10. Cunningham MT, Brandt JT, Chandler WL, Eby CS, Hayes TE, Krishnan J, et al. Quality assurance in hemostasis: the perspective from the College of American Pathologists proficiency testing program. Semin Thromb Hemost. 2007:33(3):250-8.

11. Nanduri S, Tayal AH, Hegde GG, Shang J, Venkat A. An analysis of discrepancy between point-of-care and central laboratory international normalized ratio testing in ED patients with cerebrovascular disease. Am J Emerg Med. 2012;30(9):2025-9.

12. Vazquez SR, Fleming RP, Johnson SA. Comparison of two point-of-care international normalized ratio devices and laboratory method. Blood Coagul Fibrinolysis. 2017;28(7):534-9.

13. Rosenson RS, Wolff D, Green D, Boss AH, Kensey KR. Aspirin. Aspirin does not alter native blood viscosity. J Thromb Haemost. 2004:2(2):340-1.

14. Staubli M, Reinhart W, Straub PW. Blood viscosity and red cell deformability after aspirin in vivo. A double-blind controlled trial. Atherosclerosis. 1982; 41(2-3):167-70.

15. Olavarria W, Delgado I, Hoppe A, Brunser A, Carcamo D, Diaz-Tapia V, et al. Validity of the NIHSS in predicting arterial occlusion in cerebral infarction is time-dependent. Neurology. 2011;76(1):62-8.

16. Chen JJ, Zhang S, Zhao YH, Jin XY, Li YB, Huang LH. Analysis on the clinical characteristics and related risk factors of patients with hemorrhagic transformation after cerebral infarction. Zhonghua Liu Xing Bing Xue Za Zhi. 2012;33(11):1176-80

17. Powers WJ, Rabinstein AA, Ackerson T, Adeoye OM, Bambakidis NC, Becker K, et al. 2018 guidelines for the early Management of Patients with Acute Ischemic Stroke: a guideline for healthcare professionals from the American Heart Association/American Stroke Association. Stroke. 2018;49(3):e46-e110.

18. Rosenson RS. Treatment with aspirin and dipyridamole is more effective than aspirin in reducing low shear blood viscosity. Microcirculation. 2008; 15(7):615-20.

19. Kowal P, Marcinkowska-Gapinska A, Elikowski W, Chalupka Z. Comparison of whole blood viscosity in vascular diseases. Pol Merkur Lekarski. 2003;15(90): 515-7.

20. Li RY, Cao ZG, Li Y, Wang RT. Increased whole blood viscosity is associated with silent cerebral infarction. Clin Hemorheol Microcirc. 2015;59(4):301-7.
21. Jeong SK, Cho Yl, Duey M, Rosenson RS. Cardiovascular risks of anemia correction with erythrocyte stimulating agents: should blood viscosity be monitored for risk assessment? Cardiovasc Drugs Ther. 2010;24(2):151-60.

22. Furukawa K, Abumiya T, Sakai K, Hirano M, Osanai T, Shichinohe $H$, et al. Increased blood viscosity in ischemic stroke patients with small artery occlusion measured by an electromagnetic spinning sphere viscometer. J Stroke Cerebrovasc Dis. 2016;25(11):2762-9.

23. Grotemeyer KC, Kaiser R, Grotemeyer KH, Husstedt IW. Association of elevated plasma viscosity with small vessel occlusion in ischemic cerebral disease. Thromb Res. 2014;133(1):96-100.

24. Kowal P, Marcinkowska-Gapinska A. Hemorheological changes dependent on the time from the onset of ischemic stroke. J Neurol Sci. 2007;258(1-2):132-6.

25. Wannamethee G, Perry IJ, Shaper AG. Haematocrit, hypertension and risk of stroke. J Intern Med. 1994;235(2):163-8.

26. Briley DP, Giraud GD, Beamer NB, Spear EM, Grauer SE, Edwards JM, et al. Spontaneous echo contrast and hemorheologic abnormalities in cerebrovascular disease. Stroke. 1994;25(8):1564-9.

27. Hitosugi M, Niwa M, Takatsu A. Changes in blood viscosity by heparin and argatroban. Thromb Res. 2001;104(5):371-4.

28. Ruef P, Gehm J, Gehm L, Felbinger C, Poschl J, Kuss N. Determination of whole blood and plasma viscosity by means of flow curve analysis. Gen Physiol Biophys. 2014;33(3):285-93.

29. Hitosugi M, Omura K, Kido M, Kawato H, Niwa M, Nagai T, et al. Changes in blood viscosity with mucopolysaccharide polysulfate. J Pharmacol Sci. 2004; 95(1):132-4.

30. Dawson DL, Zheng Q, Worthy SA, Charles B, Bradley DV Jr. Failure of pentoxifylline or cilostazol to improve blood and plasma viscosity, fibrinogen, and erythrocyte deformability in claudication. Angiology. 2002; 53(5):509-20.

31. Ciuffetti G, Lombardini R, Pirro M, Lupattelli G, Mannarino E. Clopidogrel: hemorheological effects in subjects with subclinical atherosclerosis. Clin Hemorheol Microcirc. 2001:25(1):31-9.

32. Yusuf S, Zhao F, Mehta SR, Chrolavicius S, Tognoni G, Fox KK, et al. Effects of clopidogrel in addition to aspirin in patients with acute coronary syndromes without ST-segment elevation. N Engl J Med. 2001;345(7):494-502.

33. Bhatt DL, Fox KA, Hacke W, Berger PB, Black HR, Boden WE, et al. Clopidogrel and aspirin versus aspirin alone for the prevention of atherothrombotic events. N Engl J Med. 2006;354(16):1706-17.

34. Petersen P, Boysen G, Godtfredsen J, Andersen ED, Andersen B. Placebocontrolled, randomised trial of warfarin and aspirin for prevention of thromboembolic complications in chronic atrial fibrillation. The Copenhagen AFASAK study. Lancet. 1989;1(8631):175-9.

35. Watson T, Shantsila E, Lip GY. Mechanisms of thrombogenesis in atrial fibrillation: Virchow's triad revisited. Lancet. 2009;373(9658):155-66.

36. Predictors of thromboembolism in atrial fibrillation: II. Echocardiographic features of patients at risk. The stroke prevention in atrial fibrillation investigators. Ann Intern Med 1992;116(1):6-12.

37. Marin F, Roldan V, Climent VE, Ibanez A, Garcia A, Marco P, et al. Plasma von Willebrand factor, soluble thrombomodulin, and fibrin D-dimer concentrations in acute onset non-rheumatic atrial fibrillation. Heart. 2004; 90(10):1162-6.

38. Jung JM, Lee DH, Kim KT, Choi MS, Cho YG, Lee HS, et al. Reference intervals for whole blood viscosity using the analytical performance-evaluated scanning capillary tube viscometer. Clin Biochem. 2014:47(6):489-93.

Ready to submit your research? Choose BMC and benefit from:

- fast, convenient online submission

- thorough peer review by experienced researchers in your field

- rapid publication on acceptance

- support for research data, including large and complex data types

- gold Open Access which fosters wider collaboration and increased citations

- maximum visibility for your research: over $100 \mathrm{M}$ website views per year

At $\mathrm{BMC}$, research is always in progress.

Learn more biomedcentral.com/submission 